\title{
Impact of Tobacco Smoking and Type-2 Diabetes Mellitus on Public Health: A Cerebrovascular Perspective
}

\author{
Shikha Prasad ${ }^{1}$ and Luca Cucullo ${ }^{1,2^{*}}$ \\ ${ }^{1}$ Department of Pharmaceutical Sciences, 1300 S Coulter St, Amarillo TX 79106-1712, USA \\ ${ }^{2}$ Center for Blood-Brain Barrier Research, Texas Tech University Health Sciences Center, Amarillo, TX 79106, USA
}

*Corresponding author: Luca Cucullo, Department of Chemistry, Center for Blood-Brain Barrier Research; Texas Tech University Health Sciences Center, Amarillo, TX 79106, USA, Tel: 806-414-9237; E-mail: luca.cucullo@ttuhsc.edu

Received date: November 05, 2015; Accepted date: November 07, 2015; Published date: November 12, 2015

Copyright: $\odot 2015$ Prasad S, et al. This is an open-access article distributed under the terms of the Creative Commons Attribution License, which permits unrestricted use, distribution, and reproduction in any medium, provided the original author and source are credited.

\section{Editorial}

Tobacco smoke (TS) is accountable for $\approx 434,000$ casualties/year in the US and is the leading cause of preventable death. Even though there has been a marginal decline in smoking during recent years, the fact that $\approx 18 \%$ of the US adult population are current smokers is alarming [1]. In 2007 diabetes was the 7th leading cause of death in the US and increasing at an alarming rate. One in every three U.S. adults is projected to suffer from diabetes by 2050 [2]. Smoking is a major risk factor for diabetes [3], with 12\% of Type-2 Diabetes Mellitus (T2DM) cases being attributed to tobacco smoke (45\% higher in men, $74 \%$ higher in women in comparison to non-smokers) [4-6]. Both active and passive smoking not only causes glucose intolerance [7], but also significantly increases the risk of diabetes. Major pathological changes in diabetic patients such as insulin resistance and high levels of glycated hemoglobin (HbAlc) have also been reported in smokers [5]. Similarly to TS, the risk of myocardial infarction and stroke is 4 -fold higher in 2DM independently of other known risk factors [8]. Both $\mathrm{T} 2 \mathrm{DM}$ and TS have independently been reported to enhance the risk of cerebrovascular and neurological disorders, however the pathophysiological mechanisms underlying these cerebrovascular disorders remain elusive. CS contains over 4000 chemicals including nicotine and various reactive oxygen species (ROS) (e.g., $\mathrm{H}_{2} \mathrm{O}_{2}$, epoxides, nitrogen dioxide, peroxynitrite -ONOO-, etc. $[9,10]$ which pass through the lung alveolar wall and raise systemic oxidative stress OS [11]. At the cerebrovascular level this promotes oxidative damage and $\mathrm{BBB}$ breakdown via tight junction (TJ) modification and activation of pro inflammatory pathways $[12,13]$. Under normal conditions, ROS are scavenged by antioxidant vitamins such as ascorbic acid and $\alpha$-tocopherol [14-17] or intracellularly converted into less reactive molecules by superoxide dismutase (SOD), catalase, and glutathione peroxidase (GSH-Px) [18]. Both acute and chronic nicotine exposure has even shown to reduce stroke induced enhancement in GLUT1 transport function and expression at the BBB in a focal brain ischemia model [19]. However, chronic exposure to active and passive smoking can overwhelm these protective mechanisms. Elevated levels of WBC, primarily neutrophils and monocytes, are observed in smokers [20]. In particular, neutrophils, which secrete free radicals, elastase and collagenase [21], are thought to contribute directly to endothelial cells (EC) injury. Platelet activation is also frequently observed in smokers [22] and confirmed in vitro and in vivo studies [23].

Chronic hyperglycemia, a pathogenic alteration characteristic of T2DM, also causes endogenous ROS increase by inhibiting glycolysis and promoting the formation of harmful intermediates (such as advanced glycation end products (AGEs) and protein kinase-C pathway (PKC) isoforms) which have DNA and protein damaging effects [24-26]. T2DM causes endothelial dysfunction leading to BBB impairment and loss of barrier integrity [26].

\section{Effects of Oxidative Stress by Hyperglycaemia}

Glucose is the primary source of energy for the brain, which consumes around $25 \%$ of the total glucose available in the body. Diabetes is generally characterized by hyperglycemia followed by a sharp decline in plasma glucose levels upon administration of insulin injection/anti-diabetic medication [26]. A state of hyperglycemia particularly damages endothelial cells and those similar where the glucose transporter expression does not decline in proportion to the excess glucose available, thereby leading to an increase in intracellular glucose [24]. Excess glucose and free fatty acid flux from adipocytes to macrovascular endothelial cells resulting in mitochondrial overproduction of ROS. Increased ROS levels activate poly-ADPribose polymerase-1(PARP-1) causing an inhibition of glyderaldehyde-3-phosphate dehydrogenase (GAPDH) by poly-ADPribosylation, thereby impeding the progress of glycolysis and increasing the presence of glycolytic intermediates. These intermediates enter into several by-pathways like polyol, hexosamine, protein kinase-C (PKC) and advanced glycation end products (AGE) pathways. The resulting effects translate into either utilization of important enzymes like aldose reductase or formation of unwanted intermediates like AGEs and PKC isoforms, which have damaging effects on DNA such as DNA strand breakage [27-30], and nitric oxide (NO) and antioxidant depletion which similarly to tobacco smoke can impact the viability of the cerebrovascular system and promote inflammation. Recent observations suggest that ROS are key mediators of BBB breakdown [31].

\section{Role of HMGB1 in Oxidative Stress-Dependent BBB Damage}

HMGB1 is a prototypic damage-associated molecular pattern (DAMP) protein highly secreted by activated macrophages and monocytes as a cytokine mediator of inflammation. This DNA-binding nuclear protein is released both passively during cell death and actively following cytokine stimulation. It is also implicated in both infectious and sterile inflammatory disorders [32-36] affecting the central nervous system (CNS) such as in Parkinson's disease (PD) [37], multiple sclerosis (MS) $[38,39]$, ischemic stroke [40], traumatic brain injury (TBI) [41] and Alzheimer's disease - AD [42-44]. HMGB1 activates cells by differential engagement of several membrane receptors including advanced glycation end products (RAGE), toll-like receptor 2 (TLR2), and TLR4 which are primarily responsible for HMGB1 pro-inflammatory activity and BBB impairment $[45,46]$. Specific to the proposed work, several studies have clearly outlined the 
role of OS in the development of microvascular and cardiovascular complications of 2DM [47]. These underpin the primary role of HMGB1 $[48,49]$ and the receptor for advanced glycation end-products (RAGE) $[50,51]$ in the onset of 2DM-mediated inflammatory vascular damage $[52,53]$ and BBB dysfunction $[13,26]$. Along a similar line, TSdependent cerebrovascular damage has been linked to smokingdependent generation of ROS and oxidative stress [12,54-56] which may support the possible activation of a similar pathogenic course also involving HMGB1 [57] and RAGE activation leading to the development of CNS degenerative disorders [43]. HMGB1 can directly impact $\mathrm{BBB}$ integrity thereby exposing the brain to inflammatory, toxic or other circulating substances. By directly penetrating the brain microvasculature, HMGB1 can then bind to glial and/or neuronal receptors on microglia and astrocytes, leading to changes in their functional phenotype [58].

\section{Neuroprotective Role of Nrf2 in oxidative stress-dependent BBB damage}

Based on a recent gene array study by our lab [59], alteration of Nrf2-ARE pathways were among the most predominant gene transcription/translation changes we observed in human BBB microvascular endothelial cells exposed either to TS or 2DM-like altered glycaemic conditions (hyperglycaemia) [60]. These include Nrf2 nuclear translocation in BBB endothelium; upregulation of Nrf2ARE dependent Phase I and II detoxification genes; and upregulated synthesis and activity of various antioxidant enzymes. Further, emerging evidence indicates a neuroprotective role of nuclear-factor (erythroid derived 2) related factor-2 (Nrf2) signaling in preventing cerebrovascular dysfunction associated with several CNS pathologies. In fact, Nrf2 activation alleviates early brain injury and cognitive dysfunction in experimental models of subarachnoid hemorrhage and traumatic brain injury [61]. Defective Nrf2-dependent redox signaling has been implicated in microvascular dysfunction in both 2DM [62] and CS [63]. From this perspective drugs enhancing Nrf2-ARE which promote increased translocation of Nrf2 in the nucleus, increased degradation of its binding Keap1, increase in downstream activity such as increased GSH and/or enzymes such as NQO-1, HO-1 [64-66] may hold promise in future to reduce the BBB injury outcome in chronic smoking and T2DM population and perhaps provide therapeutic benefits for the treatment of neurovascular disorders (e.g., stroke) where oxidative stress and inflammation play a prodromal role.

\section{References}

1. Centers for Disease Control and Prevention (2014) The Health Consequences of Smoking-50 Years of Progress: A Report of the Surgeon General.

2. Successes and Opportunities for Population-Based Prevention and Control At A Glance 2011.

3. Willi C, Bodenmann P, Ghali WA, Faris PD, Cornuz J (2007) Active smoking and the risk of type 2 diabetes: a systematic review and metaanalysis. JAMA 298: 2654-2664.

4. Haire-Joshu D, Glasgow RE, Tibbs TL (1999) Smoking and diabetes. Diabetes Care 22: 1887-1898.

5. Chang SA (2012) Smoking and type 2 diabetes mellitus. Diabetes Metab J 36: 399-403.

6. Ding EL, Hu FB (2007) Smoking and type 2 diabetes: underrecognized risks and disease burden. JAMA 298: 2675-2676.

7. Houston TK, Person SD, Pletcher MJ, Liu K, Iribarren C, et al. (2006) Active and passive smoking and development of glucose intolerance among young adults in a prospective cohort: CARDIA study. BMJ 332: 1064-1069.

8. Haffner SM, Lehto S, Ronnemaa T, Pyorala K, Laakso M (1998) Mortality from coronary heart disease in subjects with type 2 diabetes and in nondiabetic subjects with and without prior myocardial infarction. $\mathrm{N}$ Engl J Med 339: 229-234.

9. Pryor WA, Stone K (1993) Oxidants in cigarette smoke. Radicals, hydrogen peroxide, peroxynitrate, and peroxynitrite. Ann N Y Acad Sci 28: $12-27$.

10. Valavanidis A, Vlachogianni T, Fiotakis K (2009) Tobacco smoke: involvement of reactive oxygen species and stable free radicals in mechanisms of oxidative damage, carcinogenesis and synergistic effects with other respirable particles. Int J Environ Res Public Health 6: 445-462.

11. Yamaguchi Y, Nasu F, Harada A, Kunitomo M (2007) Oxidants in the gas phase of cigarette smoke pass through the lung alveolar wall and raise systemic oxidative stress. J Pharmacol Sci 103:275-282.

12. Naik P, Fofaria N, Prasad S, Sajja RK, Weksler B, et al. (2014) Oxidative and pro-inflammatory impact of regular and denicotinized cigarettes on blood brain barrier endothelial cells: is smoking reduced or nicotine-free products really safe? BMC Neurosci 15: 51.

13. Pun PB, Lu J, Moochhala S (2009) Involvement of ROS in BBB dysfunction. Free Radic Res 43: 348-364.

14. Chiu HJ, Fischman DA, Hammerling U (2008) Vitamin A depletion causes oxidative stress, mitochondrial dysfunction, and PARP-1dependent energy deprivation. FASEB J 22: 3878-3887.

15. Davitashvili DT, Museridze DP, Svanidze IK, Pavliashvili NS, Sanikidze TV (2010) Correction of oxidative stress in the rat brain cortical cellular culture with vitamines E and C. Georgian Med News 180: 56-60.

16. Gallo C, Renzi P, Loizzo S, Loizzo A, Piacente S, et al. (2010) Potential therapeutic effects of vitamin $\mathrm{e}$ and $\mathrm{C}$ on placental oxidative stress induced by nicotine: an in vitro evidence. Open Biochem J 4: 77-82.

17. Tsuneki H, Sekizaki N, Suzuki T, Kobayashi S, Wada T, et al. Coenzyme Q10 prevents high glucose-induced oxidative stress in human umbilical vein endothelial cells. Eur J Pharmacol 566: 1-10.

18. Hayes JD, Strange RC (1995) Potential contribution of the glutathione Stransferase supergene family to resistance to oxidative stress. Free Radic Res 22: 193-207.

19. Shah KK, Boreddy PR, Abbruscato TJ (2015) Nicotine pre-exposure reduces stroke-induced glucose transporter-1 activity at the blood-brain barrier in mice. Fluids Barriers CNS 12:10.

20. Masubuchi T, Koyama S, Sato E, Takamizawa A, Kubo K, et al. (1998) Smoke extract stimulates lung epithelial cells to release neutrophil and monocyte chemotactic activity. Am J Pathol 153: 1903-1912.

21. Palmblad J (1984) The role of granulocytes in inflammation. Scand J Rheumatol 13: 163-172.

22. Togna AR, Latina V, Orlando R, Togna GI (2008) Cigarette smoke inhibits adenine nucleotide hydrolysis by human platelets. Platelets 19: 537-542.

23. Girdhar G, Xu S, Jesty J, Bluestein D (2008) In vitro model of plateletendothelial activation due to cigarette smoke under cardiovascular circulation conditions. Ann Biomed Eng 36: 1142-1151.

24. Brownlee M (2005) The pathobiology of diabetic complications: a unifying mechanism. Diabetes 54: 1615-1625.

25. Maria-Luisa Lazo-de-la-Vega-Monroy, Cristina Fernández-Mejía (2013) Oxidative Stress in Diabetes Mellitus and the Role Of Vitamins with Antioxidant Actions. In Intech 209-225.

26. Prasad S, Sajja RK, Naik P, Cucullo L (2014) Diabetes Mellitus and BloodBrain Barrier Dysfunction: An Overview. Journal of Pharmacovigilance 2: 125.

27. Chen HW, Chien ML, Chaung YH, Lii CK, Wang TS (2004) Extracts from cigarette smoke induce DNA damage and cell adhesion molecule expression through different pathways. Chem Biol Interact 150: 233-241.

28. Pryor WA, Stone K, Zang LY, Bermudez E (1998) Fractionation of aqueous cigarette tar extracts: fractions that contain the tar radical cause DNA damage. Chem Res Toxicol 11: 441-448. 
29. Stone K, Bermudez E, Zang LY, Carter KM, Queenan KE, et al. (1995) The ESR properties, DNA nicking, and DNA association of aged solutions of catechol versus aqueous extracts of tar from cigarette smoke. Arch Biochem Biophys 319: 196-203.

30. DeMarini DM (2004) Genotoxicity of tobacco smoke and tobacco smoke condensate: a review. Mutat Res 567: 447-474.

31. Pun PB, Lu J, Moochhala S (2009) Involvement of ROS in BBB dysfunction. Free Radic Res 43: 348-364.

32. Yang H, Tracey KJ (2005) High mobility group box 1 (HMGB1). Crit Care Med 33: S472-S474.

33. Bianchi ME, Manfredi AA (2007) High-mobility group box 1 (HMGB1) protein at the crossroads between innate and adaptive immunity. Immunol Rev 220: 35-46.

34. Raucci A, Palumbo R, Bianchi ME (2007) HMGB1: a signal of necrosis. Autoimmunity 40: 285-289.

35. Bianchi ME (2007) DAMPs, PAMPs and alarmins: all we need to know about danger. J Leukoc Biol 81: 1-5.

36. Andersson U, Tracey KJ (2011) HMGB1 is a therapeutic target for sterile inflammation and infection. Annu Rev Immunol 29: 139-1362.

37. Song JX, Lu JH, Liu LF, Chen LL, Durairajan SS, et al. (2014) HMGB1 is involved in autophagy inhibition caused by SNCA/alpha-synuclein overexpression: a process modulated by the natural autophagy inducer corynoxine B. Autophagy 10: 144-154.

38. Robinson AP, Caldis MW, Harp CT, Goings GE, Miller SD (2013) Highmobility group box 1 protein (HMGB1) neutralization ameliorates experimental autoimmune encephalomyelitis. J Autoimmun 43: 32-43.

39. Andersson A, Covacu R, Sunnemark D, Danilov AI, Dal BA, et al. (2008) Pivotal advance: HMGB1 expression in active lesions of human and experimental multiple sclerosis. J Leukoc Biol 84: 1248-1255.

40. Kim JB, Sig CJ, Yu YM, Nam K, Piao CS, et al. (2006) HMGB1, a novel cytokine-like mediator linking acute neuronal death and delayed neuroinflammation in the postischemic brain. J Neurosci 26: 6413-6421.

41. Okuma Y, Liu K, Wake H, Zhang J, Maruo T, et al. (2012) Anti-high mobility group box-1 antibody therapy for traumatic brain injury. Ann Neurol 72: 373-384.

42. Takata K, Takada T, Ito A, Asai M, Tawa M, et al. (2012) Microglial Amyloid- $\beta-40$ Phagocytosis Dysfunction Is Caused by High-Mobility Group Box Protein-1: Implications for the Pathological Progression of Alzheimer's Disease. Int J Alzheimers Dis 2012: 685739.

43. Fang P, Schachner M, Shen YQ (2012) HMGB1 in development and diseases of the central nervous system. Mol Neurobiol 45: 499-506.

44. Takata K, Kitamura Y, Tsuchiya D, Kawasaki T, Taniguchi T, et al. (2004) High mobility group box protein-1 inhibits microglial Abeta clearance and enhances Abeta neurotoxicity. J Neurosci Res 78: 880-8891.

45. Luo Y, Li SJ, Yang J, Qiu YZ, Chen FP (2013) HMGB1 induces an inflammatory response in endothelial cells via the RAGE-dependent endoplasmic reticulum stress pathway. Biochem Biophys Res Commun 438: 732-738.

46. Chuah YK, Basir R, Talib H, Tie TH, Nordin N (2013) Receptor for Advanced Glycation End Products and Its Involvement in Inflammatory Diseases. Int J Inflam 2013: 403460.

47. Giacco F, Brownlee M (2010) Oxidative stress and diabetic complications Circ Res 107: 1058-1070.

48. Chen XL, Zhang XD, Li YY, Chen XM, Tang DR, et al. Involvement of HMGB1 mediated signalling pathway in diabetic retinopathy: evidence from type 2 diabetic rats and ARPE-19 cells under diabetic condition. B J Ophthalmol 97: 1598-1603.
49. Chen Y, Qiao F, Zhao Y, Wang Y, Liu G (2015) HMGB1 is activated in type 2 diabetes mellitus patients and in mesangial cells in response to high glucose. Int J Clin Exp Pathol 8: 6683-6691.

50. Manigrasso MB, Juranek J, Ramasamy R, Schmidt AM (2014) Unlocking the biology of RAGE in diabetic microvascular complications. Trends Endocrinol Metab 25: 15-22.

51. Ramasamy R, Yan SF, Schmidt AM (2011) Receptor for AGE (RAGE): signaling mechanisms in the pathogenesis of diabetes and its complications. Ann N Y Acad Sci 1243: 88-102.

52. Tobon-Velasco JC, Cuevas E, Torres-Ramos MA (2014) Receptor for AGEs (RAGE) as mediator of NF-kB pathway activation in neuro inflammation and oxidative stress. CNS Neurol Disord Drug Targets 13: 1615-1626.

53. Chuah YK, Basir R, Talib H, Tie TH, Nordin N (2013) Receptor for advanced glycation end products and its involvement in inflammatory diseases. Int J Inflam 2013: 403460.

54. Arnson Y, Shoenfeld Y, Amital H (2010) Effects of tobacco smoke on immunity, inflammation and autoimmunity. J Autoimmun 34: J258-J265.

55. Dietrich M, Block G, Norkus EP, Hudes M, Traber MG, et al. (2003) Smoking and exposure to environmental tobacco smoke decrease some plasma antioxidants and increase gamma-tocopherol in vivo after adjustment for dietary antioxidant intakes. Am J Clin Nutr 77: 160-166.

56. Hossain M, Mazzone P, Tierney W, Cucullo L (2011) In vitro assessment of tobacco smoke toxicity at the BBB: do antioxidant supplements have a protective role? BMC Neurosci 12: 92.

57. Yu Y, Tang D, Kang R (2015) Oxidative stress-mediated HMGB1 biology. Front Physiol 6: 93.

58. Pedrazzi M, Patrone M, Passalacqua M, Ranzato E, Colamassaro D, et al. (2007) Selective proinflammatory activation of astrocytes by highmobility group box 1 protein signaling. J Immunol 179: 8525-8532.

59. Naik P, Sajja RK, Prasad S, Cucullo L (2015) Effect of full flavor and denicotinized cigarettes exposure on the brain microvascular endothelium: a microarray-based gene expression study using a human immortalized BBB endothelial cell line. BMC Neurosci 16: 38.

60. Prasad S, Sajja RK, Park JH, Naik P, Kaisar MA, et al. (2015) Impact of cigarette smoke extract and hyperglycemic conditions on blood-brain barrier endothelial cells. Fluids Barriers CNS 12: 18

61. Liu Y, Qiu J, Wang Z, You W, Wu L, et al. (2015) Dimethylfumarate alleviates early brain injury and secondary cognitive deficits after experimental subarachnoid hemorrhage via activation of Keap1-Nrf2ARE system. J Neurosurg 123: 915-923.

62. Balligand JL (2013) Reducing damage through Nrf-2. Cardiovasc Res 100: 1-3.

63. Cantin AM (2010) Cellular response to cigarette smoke and oxidants: adapting to survive. Proc Am Thorac Soc 7: 368-375.

64. Hayes JD, Dinkova-Kostova AT (2014) The Nrf2 regulatory network provides an interface between redox and intermediary metabolism. Trends Biochem Sci 39: 199-218.

65. Nguyen T, Nioi P, Pickett CB (2009) The Nrf2-antioxidant response element signaling pathway and its activation by oxidative stress. J Biol Chem 284: 13291-13295.

66. Tanigawa S, Fujii M, Hou DX (2007) Action of Nrf2 and Keap1 in AREmediated NQO1 expression by quercetin. Free Radic Biol Med 42: 1690-1703. 